\title{
PÓS-GRADUAÇÃO EM CINEMA: UM ROTEIRO TEÓRICO-PRÁTICO EM EDUCAÇÃO A DISTÂNCIA
}

\author{
SÃO PAULO/SP JUNHO/2018
}

\author{
Francisco Carlos Tadeu Starke Rodrigues - Belas Artes - francisco.starke@belasartes.br \\ Guilherme Bryan - Belas Artes - guilherme.bryan@belasartes.br \\ Jacqueline de Oliveira Lameza - Belas Artes - jacqueline.lameza@belasartes.br \\ João Tenório da Silva - Belas Artes - joao.tenorio@belasartes.br \\ Lucas de Mattos Millan - Belas Artes - lucas.millan@belasartes.br
}

Tipo: Relato de Experiência Inovadora (EI)

Categoria: Métodos e Tecnologias

Setor Educacional: EDUCAÇÃO SUPERIOR

\begin{abstract}
RESUMO
O presente artigo relata o processo de concepção do Curso de Pós-Graduação em Cinema EaD do Centro Universitário Belas Artes, cuja principal diretriz consiste em oferecer ao aluno uma experiência acadêmica teórico-prática abrangente e referência em qualidade no mercado de cursos na modalidade a distância no Brasil. Neste artigo, portanto, justificam-se as escolhas curriculares, de design instrucional e de design multimídia, além de apresentar-se os resultados da pesquisa de reação, essenciais para o aprimoramento futuro.
\end{abstract}

Palavras-chave: Cinema. Pós-graduação. EaD. Educação a Distância. 


\section{CONSIDERAÇÕES INICIAIS}

Nesta segunda década do século XXI, os estudos das produções audiovisuais têm apontado para uma multiplicação de telas, o que faz com que muitos realizadores e grandes produtoras pensem em novas estratégias, inclusive de linguagem, para se comunicar com mais eficiência com novos públicos. Por sua vez, houve um barateamento dos equipamentos de filmagem e dos softwares de edição, o que resultou numa maior possibilidade de que muitas pessoas se aventurassem a realizar filmes e outros tipos de produtos audiovisuais (LIPOVETSKY; SERROY, 2009). Desse modo, a matriz curricular foi organizada em quatro frentes principais.

A primeira frente tem como intuito levar o estudante a conhecer e refletir a respeito do atual mercado audiovisual, com ênfase no Brasil, entrando em contato, por exemplo, com as formas de produção (valendo-se das leis de incentivo proporcionadas pelo governo nos âmbitos municipal, estadual e federal), de distribuição (pensando nas janelas de exibição e na nova frente aberta pela internet e por plataformas como o Youtube e o Netflix) e de exibição (como, por exemplo, o desenvolvimento de uma nova dimensão da imagem resultante das gravações pelos dispositivos móveis). Com esse intuito, pensamos nas disciplinas Cinema Digital e Produção e Distribuição (ambas na modalidade a distância) e Financiamento e Captação de Recursos (presencial, como uma oficina de seis horas, com foco, por exemplo, na inscrição de editais).

Em conjunto com essa frente, temos as disciplinas institucionais, que carregam a essência de todos os cursos do Centro Universitário Belas Artes de São Paulo. São elas Economia Criativa e Cidades, Empreendedorismo, Designing Your Life e Metodologia de Pesquisa Científica. Seus principais objetivos incluem despertar e incentivar a criatividade dos alunos, assim como torná-los empreendedores capazes de desenvolver seus próprios negócios na área audiovisual. Esse intuito está totalmente de acordo com o atual momento do audiovisual em que as produtoras brasileiras com mais visualizações e assinantes no Youtube, por exemplo, surgiram no modelo de startups. São elas, a KondZilla, criada pelo diretor Konrad Dantas e voltada principalmente para o segmento musical do funk ostentação; e a Bromélia Filmes, produtora responsável pelos videoclipes infantis estrelados pela Galinha Pintadinha.

A segunda frente é voltada à historiografia do cinema nos principais centros de produção mundiais - Estados Unidos e Europa - e no Brasil. O principal objetivo dessas três disciplinas é demonstrar aos estudantes como é importante para eles terem referências para realizarem seus próprios trabalhos. Acreditamos que, sem esse conhecimento do que já foi realizado de mais importante pelos principais realizadores ao longo da história, torna-se praticamente impossível ser criativo e inovador na área audiovisual.

A terceira frente conta com disciplinas que ensinam, de modo geral, como é realizado um filme, desde a etapa da pré-produção e elaboração do roteiro, até a pós-produção e a edição de som e imagem, aliada à inserção de efeitos visuais e sonoros, passando pela filmagem propriamente dita. Por isso, temos as disciplinas Roteiro, Produção e Distribuição, Direção de Arte, e Edição, cada uma delas com suas especificidades e muitos exemplos práticos, utilizados em filmes bastante conhecidos e importantes, mas também pelos professores, com grande experiência prática no mercado audiovisual.

Porém, reconhecendo a dificuldade em se ministrar algumas etapas de realização no modelo a distância, optamos por oferecer algumas oficinas presenciais, tornando o encontro presencial 
um evento que vai além da simples avaliação presencial exigida por lei; trata-se de um dia de culminação da experiência acadêmica do aluno, de experiência in loco de seus tutores e colegas de curso. Elas são realizadas, em sua totalidade, nos estúdios do Laboratório de Imagem e Som (LIS) da Belas Artes e são voltadas para Direção, Direção de Fotografia e Sonoplastia e Edição de Som.

Desse modo, o intuito principal deste curso é especializar profissionais e torná-los capazes de produzir seu próprio material audiovisual, em diferentes regiões e lugares do Brasil, a partir de referências e conhecimentos aqui adquiridos, a fim de produzirem documentos importantes de registro não apenas das muitas realidades, mas também dos diversos imaginários que marcam o brasileiro. Acreditamos, assim, que quanto maior for a democratização ao acesso da produção audiovisual, valendo-se de conhecimentos adquiridos na universidade, mais fácil será a construção de uma sociedade mais plural, justa e igualitária.

\section{PROPOSTA METODOLÓGICA}

O principal objetivo desta Pós-Graduação em Cinema EaD consiste em oferecer ao aluno uma experiência acadêmica teórico-prática abrangente e referência em qualidade no mercado na modalidade a distância no Brasil. Sua concepção, portanto, levou em consideração uma série de preceitos metodológicos e interdisciplinares definidos, tal e como será exposto a seguir, pelas competências do conjunto de membros do Departamento de Educação a Distância da Belas Artes, a fim de potencializar sua qualidade.

\subsection{Design instrucional}

O modelo de design instrucional adotado no curso de Cinema é fechado. Nele, o Designer Instrucional começa a trabalhar em uma tela vazia e toma todas as decisões relacionadas às partes do fluxo de aprendizagem - que serão automatizadas - às regras de estruturação, às interações sociais e ao grau dessas interações, tudo mediante critérios institucionais qualiquantitativos claros e inalteráveis, conforme cita Filatro (2008). Trata-se de um modelo imersivo, com o conteúdo estudado via internet e com a interação entre alunos e tutores feita de maneira on-line por meio do Ambiente Virtual de Aprendizagem (AVA) da webAula a cada Módulo com duração de 2 meses. Finalmente, os Módulos são concluídos com um encontro presencial composto pela avaliação presencial (4h) e uma oficina (6h).

Apesar da natureza fechada do design instrucional, o aluno dispõe de feedbacks personalizados e contextualizados. Para tal, requer-se a participação de um Professor Tutor durante todo o percurso, característica do design instrucional contextualizado (FILATRO, 2007). Apenas as autoavaliações e as avaliações a distância contam com correção e feedbacks automatizados, os quais, por sua vez, potencializam a autonomia do aluno.

Foi definida uma pré-estrutura que contempla quatro unidades, cada uma delas contendo introdução, objetivos desenvolvidos a partir da taxonomia de Bloom, desenvolvimento de um assunto específico dividido em cinco seções. Cada seção conta com uma videoaula, a fim de garantir que o aluno possa conciliar o conhecimento teórico adquirido na leitura com a contextualização prática e com o aprofundamento proposto, conforme enfatizado por Machado e Moraes (2015). Além disso, um vídeo introduz e outro encerra cada unidade, reforçando a 
presença do autor como guia da disciplina. Para cada unidade, quatro atividades avaliativas: Fórum de Discussão, que foca em um processo avaliativo interativo e colaborativo; Trabalho, que consiste em atividades práticas, momento em que o aluno desenvolve, pouco a pouco, uma etapa do seu projeto de audiovisual, sempre com a devolutiva do Tutor EaD, uma premissa básica para que o aluno possa ir crescendo a cada unidade; e avaliação da unidade, que possui caráter conceitual.

Um ponto alto do curso, apesar de ser não avaliativo, é o Chat semanal. Nele, um tema é lançado com antecedência, motivando os alunos a participar dando ideias, trocando experiências, contribuindo com sugestões etc. Este chat acontece via WhatsApp, escolhido pela sua praticidade e agilidade, integrando o curso ao quotidiano dos alunos. Tendo em mente justamente essa maior acessibilidade, optou-se, em todo o curso, por uma linguagem dialógica, por sua capacidade de aproximar alunos e professor.

Definido o tipo de design instrucional, a preocupação foi disponibilizar para esse público um curso dinâmico, com diversas interações dentro e entre as páginas em HTML5, com vídeos que fossem um diferencial na mais perfeita integração entre as mídias, que funcionassem como uma pílula que fornecessem um reforço dos pontos principais. Vídeos curtos (entre $1 \mathrm{~min} 30 \mathrm{~s}$ e 2min), no tempo da internet e dos dispositivos móveis, que facilitassem o exercício da autonomia do aluno, que poderia decidir a quanto de conteúdo iria se dedicar por vez. A opção pelo uso de elementos periféricos favoreceu a arquitetura da informação: Multimídia, Mais, Reflexão, Atenção, Curiosidade e Glossário, cada um deles em locais estratégicos para despertar a curiosidade do aluno e garantir a imersão no conteúdo trabalhado. Como afirmam Lima, Silva e Paiva (2010), o aluno precisa ser incentivado a exercitar sua autonomia para garantir sua aprendizagem. Cabe a ele decidir se irá acessar esses mecanismos motivacionais para completar seu aprendizado.

Para a roteirização das telas em HTML5, o design instrucional considerou as diversas estratégias pedagógicas para que o aluno pudesse assimilar o conteúdo de uma forma intuitiva. A teoria escolhida para o curso de Cinema foi a cognitivista, com enfoque na teoria de inteligências múltiplas, conforme destacado por Kenski e Schultz (2015), já que o conteúdo apresentado em cada seção foi desenvolvido através de diversos recursos: textos, videoaulas, trocas de experiências entre os alunos e experimentação nas atividades de cada uma das unidades. Tudo isso levando-se em consideração que o aluno aprende melhor quando trabalha com uma variedade de métodos e ferramentas. Para o storyboard, foi pensada uma série de ferramentas de interatividade, a fim de minimizar a fadiga na leitura e preocupando-se, ao mesmo tempo, em não sobrecarregar o aluno de estímulos, o que também pode ser prejudicial ao aprendizado. Em todo o processo de produção dos materiais, o design instrucional levou em consideração alguns pontos importantes para que o curso pudesse, de fato, ser um sucesso: uso da linguagem dos apaixonados por cinema; design funcional e esteticamente contextualizado ao conteúdo; estímulo do aprendizado em grupo e individual por meio de atividades relevantes, interessantes e tutoria ativa.

Ao fim de cada Módulo, há um encontro presencial com um intuito duplo: avaliar os conhecimentos adquiridos ao longo das três disciplinas e oferecer aos alunos uma experiência que resultasse na culminação de sua etapa de aprendizado. Para isso, durante uma jornada 
letiva presencial, eles se unem em grupos e, sob a tutela dos três professores que tiveram durante a etapa on-line, realizam um projeto que integre conceitos e técnicas apreendidos durante o Módulo.

\subsection{Design multimídia}

Cada disciplina do curso de Cinema possui uma identidade visual diferente, com background, imagens, ícone e vídeo colaborando para o ensino. Essa linguagem visual pedagógica transcende o layout padrão "default" de um Learning Management System (LMS). Para navegar pelo material didático on-line de cada disciplina dentro do Ambiente Virtual de Aprendizagem (AVA), o aluno desliza pelas páginas HTML5 - na Belas Artes chamamos o material de Easy Scroll Interativo. Esse efeito "parallax" é, na verdade, uma forma de enganar nosso cérebro utilizando objetos de tamanhos diferentes e com velocidades diferentes para criar um aspecto de profundidade. $\mathrm{O}$ ato de deslizar o dedo, ou "scrollar" o mouse, é um hábito tão presente entre a população familiarizada com recursos digitais que sua integração ao material didático foi um caminho óbvio, a fim de potencializar a familiaridade do aluno.

As disciplinas podem ser acessadas em dispositivos móveis, já que o material didático on-line é responsivo. O aluno também pode acessar o conteúdo de maneira off-line, através de um ebook que é o mesmo conteúdo presente no Easy Scroll Interativo, adequado, porém, ao novo formato, sem suas interatividades e com seu próprio trabalho de diagramação. O AVA conta também com banners, agenda, manual do aluno e folha de resposta padronizada para 0 trabalho; as identidades visuais de todos esses itens são customizadas segundo a disciplina, sempre em harmonia com a totalidade do Curso.

Foram vários testes para o projeto da identidade: tipografias variadas que remetessem a rolos de filme, ou parecidos aos cartazes no estilo Art Déco. Testamos usar a cena do filme $A$ chegada de um trem à estação (Irmãos Lumière, 1895), onde um trem se move em direção ao público que assiste, causando medo e tumulto. O uso desta imagem poderia ocasionar, porém, uma imagem errônea sobre o curso, já que não trata apenas da história. Pensando nisso, os profissionais de design da $\mathrm{EaD}$ da Belas Artes optaram por usar uma imagem abstrata de fundo, remetendo à modernidade e à criatividade. Neste background, foi usada uma paleta de cores extraído do resultado da experiência do painel semântico a seguir.

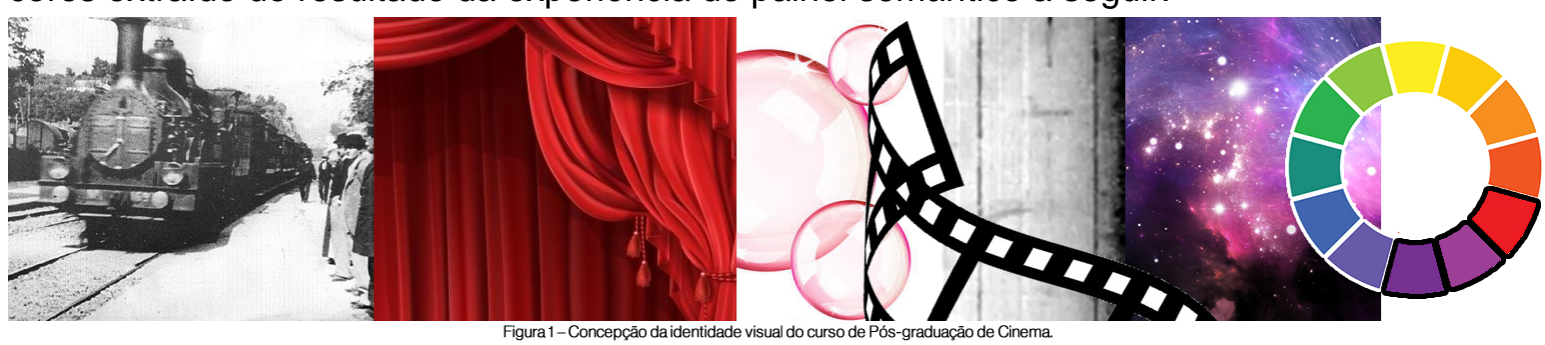

A cor vermelha é fortemente reconhecida através das cortinas de palcos de teatro, a raiz de um objeto semiótico que representa origem do cinema nas grandes telas. Vermelho também indica elegância e atenção por ser uma cor intensa. A cor é considerada um recurso expressivo poderosíssimo, capaz de retratar sentimentos, personalidades e, até mesmo, arcos narrativos. Por exemplo, em Moulin Rouge (2001), a paixão era representada, justamente, pela cor vermelha. Assim, o vermelho (cor primária) entrelaça-se com o dégradécom as cores vermelho- 
arroxeado (cor terciária) e violeta (cor secundária); são combinações análogas, pois estão lado a lado no círculo cromático. As três cores juntas demonstram liderança, criatividade e mistério, respectivamente. Os primeiros filmes coloridos, feitos por Méliès, Pathé e Gaumont, foram feitos pintados por operários à mão no princípio, mas era muito trabalhoso conforme os filmes foram ficando maiores (DALPIZZOLO, 2007).

Também usamos a imagem do rolo de câmera de filme, aplicado às laterais do background, e a figura de círculos no centro que colaboram com ideias e imaginação, esta que nos contagia desde a infância brincando de bolha de sabão. A psicologia arquetípica, que estuda a base poética da mente, não é gerada na fisiologia do cérebro nem na estrutura da linguagem, na organização da sociedade ou na análise do comportamento, mas, conforme James Hillman (1995), nos processos da imaginação.

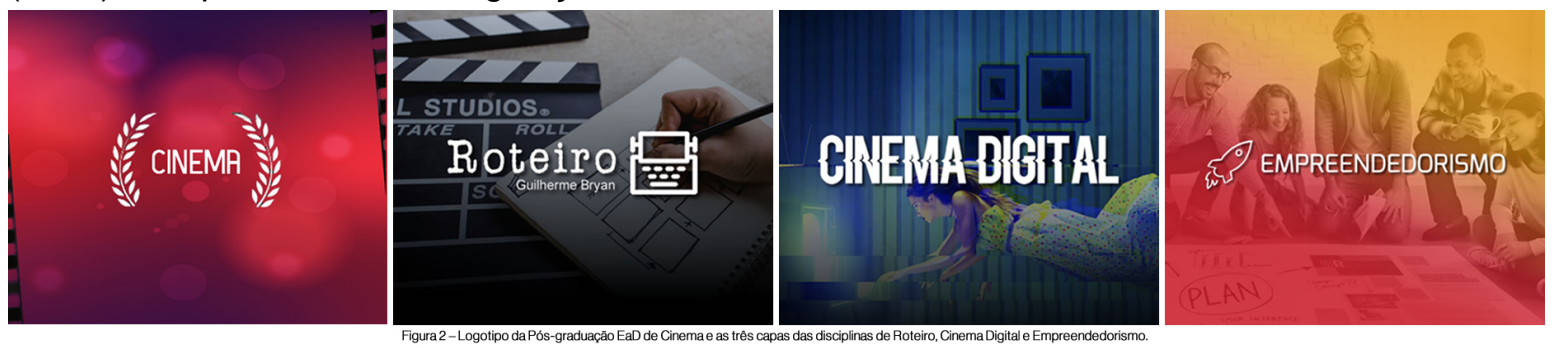

Para a tipografia do logotipo de Cinema, foi utilizada a fonte AKID sem serifa, a qual lembra a fonte de cartazes de filme antigo de Hollywood e, com estilo Art Déco, com linhas simples, estilo afinado, fácil para os olhos e de leitura confortável. O ornamento ao redor do logotipo de Cinema emula os lauréis, símbolo distintivo de premiações e festivais cinematográficos, com uma grande herança mítica da cultura greco-romana.

O material didático on-line, além de possuir conteúdo interativo com textos, imagens, vídeos, periféricos, infográficos, tabelas e autoavaliações, possui também as videoaulas. Para estas, é trabalho do Designer Multimídia desenvolver as artes que acompanham e ilustram o dito pelo professor, além das artes, frame a frame, das vinhetas de passagem. A trilha sonora teve um toque especial do profissional Produtor de Vídeos EaD, que inicia a vinheta com um mix de sons com um rolo de filme girando, logo depois de sincronizado com o som de notas de sinfonia de abertura de um espetáculo. O som do rolo de filme se repete rapidamente nas vinhetas de passagem e som da vinheta de enceramento foi usado o efeito glitch. Glitch é uma palavra em iídiche - do alemão glitschen, "deslizar", "escorregar" - que entrou na linguagem da informática para designar um mau funcionamento.

Notavelmente, o visual de uma imagem com o efeito glitch também pode ser considerado arte. O erro digital como procedimento artístico e possibilidade estética, um ponto positivo para usar no material da Belas Artes, também é chamado de "arte do till".

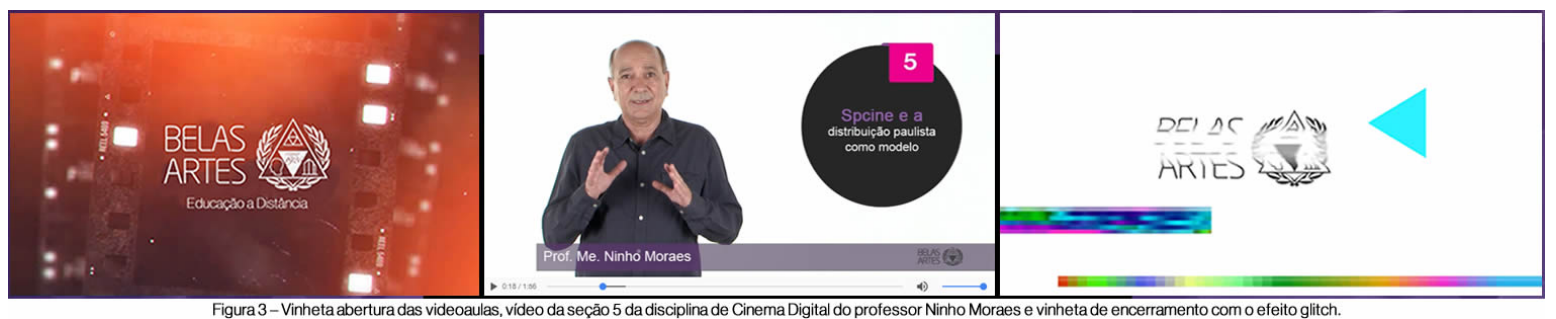




\section{AVALIAÇÃO DE REAÇÃO}

Para identificar a satisfação dos alunos diante do curso ofertado, bem como os pontos a serem melhorados, foi idealizada a Avaliação de Reação contemplando cento e trinta questões, divididas em oito grupos importantes: conteúdo, material didático, ambiente virtual, suporte $\mathrm{EaD}$, tutoria $\mathrm{EaD}$, encontro presencial, gestão do curso e gestão geral EaD. Para cada uma das três disciplinas do Módulo, foram analisados separadamente os itens: material didático, conteúdo e tutoria, que apresentaremos na média dado o espaço reduzido. Os demais itens foram analisados de modo geral. Em sua primeira edição, o curso está sendo cada vez mais bem avaliado, Módulo a Módulo. O Módulo inicial apresentou os seguintes resultados:

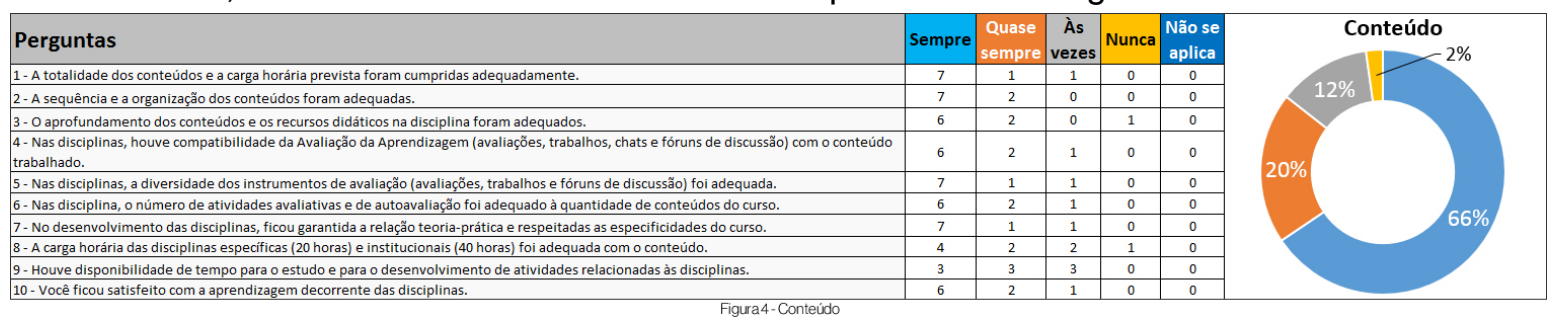

O conteúdo foi avaliado com $86 \%$ de satisfação, uma vez que é o que totaliza quando se soma "Sempre" e "Quase sempre". Os alunos avaliaram bem desde o cumprimento dos conteúdos e carga horária, bem como classificaram as atividades como compatíveis com o conteúdo e concluíram que a relação teoria-prática foi garantida, uma grande preocupação da Designer Instrucional desde o início do projeto. Os dois itens com menor avaliação foram a relação do próprio aluno em se dedicar ao estudos dos conteúdos e em relação à carga horária, ambos estão ligados. Na verdade, em conversa com os alunos nos encontros presenciais, lamentaram ter pouco tempo para a disciplina de Roteiro por ser mais prática. Individualmente, tivemos Cinema Digital com 97\%, Roteiro com 75\% e Empreendedorismo com 95\%.

\begin{tabular}{|c|c|c|c|c|c|c|}
\hline Perguntas & Sempre & $\begin{array}{l}\text { Quase } \\
\text { sempre }\end{array}$ & $\begin{array}{c}\text { Às } \\
\text { vezes }\end{array}$ & Nunca & Não se & Material didático \\
\hline $\begin{array}{l}\text { 2- Os elementos periféricos (Mais, Atenção, Multimídia, Reflexão, Na Prática, Fora da Caixa, Glossário) estavam contextualizados com o } \\
\text { conteúdo apresentado. }\end{array}$ & 8 & 1 & 0 & 0 & 0 & \\
\hline $\begin{array}{l}\text { 4- O material didático forneceu para você uma visão geral da metodologia em educação a distância a ser utilizada no curso, tendo em vista } \\
\text { ajudar seu planejamento inicial de estudos e em favor da construção de sua autonomia. }\end{array}$ & 7 & 2 & 0 & 0 & 0 & \\
\hline $\begin{array}{l}\text { 5- O material didático detallhou que competências cognitivas, habilidades e atitudes você deveria alcançar no fim de cada unidade, seção e } \\
\text { curso, oferecendo-lhe oportunidades sistemáticas de autoavaliação. }\end{array}$ & 7 & 2 & 0 & 0 & 0 & \\
\hline $\begin{array}{l}\text { 7- As avaliações estão articuladas a mecanismos que promoveram seu permanente acompanhamento, no intuito de identificar eventuais } \\
\text { dificuldades na aprendizagem e de saná-las ainda durante o processo de ensino-aprendizagem. }\end{array}$ & 5 & 4 & 0 & 0 & 0 & \\
\hline $\begin{array}{l}\text { 8- A qualidade dos materiais e da metodologia demonstrou um processo cuidadoso nas fases de planejamento, desenvolvimento, implantação } \\
\text { e avaliaçăo dos materiais disponibilizados no curso, considerando, ainda, a sua realidade e o atendimento de suas necessidades. }\end{array}$ & 6 & 3 & 0 & 0 & 0 & \\
\hline 9- As videoaulas Spot Ligth, ao final de cada seção, contribuiram para seu aprendizado. & 6 & 2 & 1 & 0 & 0 & \\
\hline 10- O material didático disponibilizado foi de boa qualidade. & 7 & 2 & 0 & 0 & 0 & \\
\hline
\end{tabular}

O material didático na soma de "Sempre" com "Quase sempre" totalizou 99\%, tendo sido avaliados itens como organização, qualidade, articulação das atividades avaliativas e de autoavaliação, e, ainda, a contribuição das videoaulas para o aprendizado.

\begin{tabular}{|c|c|c|c|c|c|c|}
\hline Perguntas & Sempre & $\begin{array}{c}\text { Quase } \\
\text { sempre }\end{array}$ & $\begin{array}{c}\text { Às } \\
\text { vezes }\end{array}$ & Nunca & $\begin{array}{r}\text { Não se } \\
\text { aplica }\end{array}$ & Ambiente Virtual \\
\hline 2- O sistema do Ambiente Virtual de Aprendizagem é estável, e não houve quedas dos servidores ou erros de comunicaç̣̃o. & 0 & 5 & 4 & 0 & 0 & \\
\hline $\begin{array}{l}\text { 3- Sua participaç̃o em atividades, como fóruns de discussão e chats, bem como as entregas de trabalho, foi simples e objetiva, sem gerar } \\
\text { dificuldades. }\end{array}$ & 5 & 2 & 2 & 0 & ${ }^{0}$ & \\
\hline 5- O Ambiente Virtual de Aprendizagem favoreceu a interatividade entre você e seus Tutores EaD. & 1 & 7 & 1 & 0 & 0 & \\
\hline 6- o Ambiente Virtual de Aprendizagem incentivou a comunicaçăo entre você e seus colegas. & 3 & 5 & 1 & 0 & 0 & \\
\hline 7- o Ambiente Virtual de Aprendizagem favoreceu aspectos relativos à orientaçăo de aprendizagem como um todo. & 7 & 2 & 0 & 0 & 0 & \\
\hline 10. OAmbiente Virtual permitiu fácil acesso a esta avaliação? & 7 & 2 & 0 & 0 & 0 & \\
\hline
\end{tabular}

Ao avaliar o Ambiente Virtual de Aprendizagem, a soma de "Sempre" com "Quase sempre" totalizou $89 \%$. O item menor avaliado foi o da estabilidade da plataforma, do servidor; 
comprova-se, porém, através do contato com os alunos através do suporte, que este fator esteja mais ligado à conexão do aluno do que por problemas de infraestrutura da plataforma. De todas formas, trabalha-se com afinco, em parceria com a plataforma webAula, para minimizar incidências e garantir que ela esteja no ar 99,9\% do tempo, conforme cláusula contratual, cabendo até mesmo a possibilidade de suporte técnico através de acesso remoto às máquinas dos alunos para um diagnóstico mais assertivo.

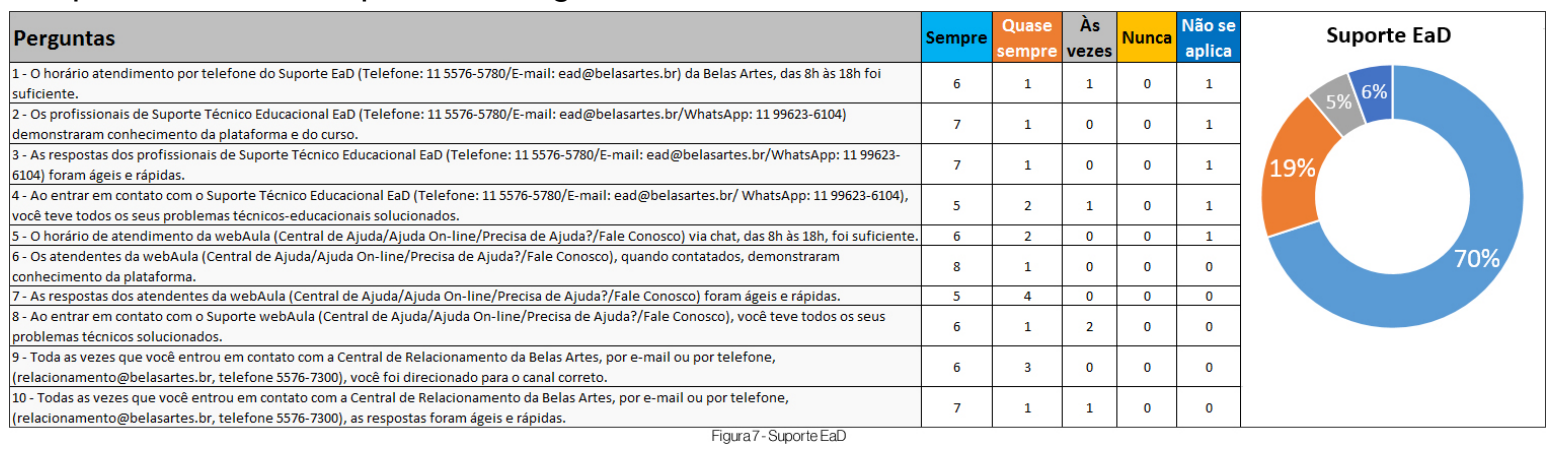

A satisfação dos alunos em relação ao Suporte Técnico-Educacional soma $89 \%$ ao incluirmos os itens "Sempre" e "Quase Sempre". Inicialmente, são três canais distintos: Central de Relacionamento, Suporte Técnico EaD, na sede do centro universitário, e Central de Ajuda da plataforma. Todos com atendimento em horário comercial, excetuando-se os fins de semana. Atendimentos por chat, e-mail e telefone que, quando acionados, cumprem seu papel, solucionando as dúvidas e resolvendo os problemas apontados pelos alunos. Mas, há um quarto canal, que ocorre via WhatsApp, que foi muito utilizado pelos alunos por sua praticidade e agilidade, uma vez que atende os alunos sete dias por semana, em período integral, incluindo fins de semana e feriados. De modo geral, cerca de $6 \%$ dos alunos quase não precisou fazer uso de parte dos canais, o que demonstra o bom entendimento da plataforma e de sua navegabilidade e estabilidade, é o que se identifica na opção "Não se aplica".

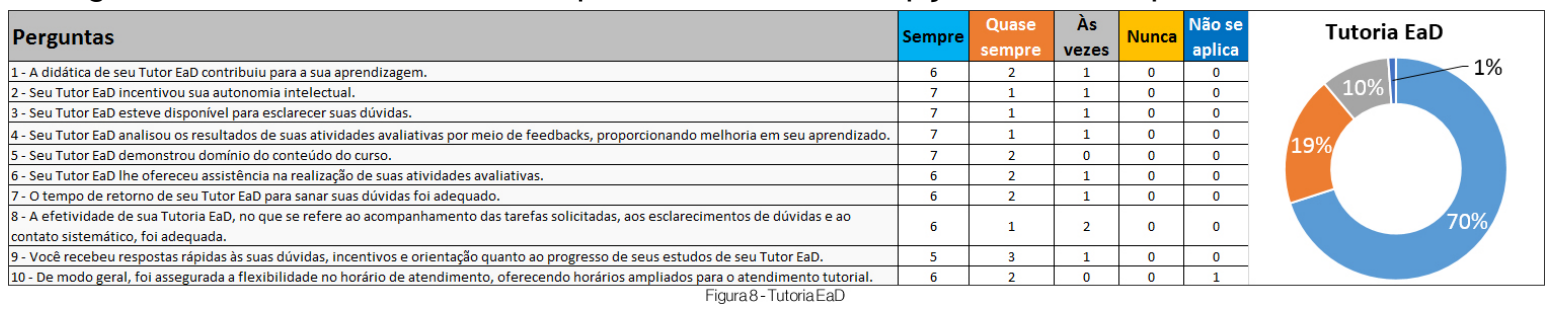

Quando questionados sobre a atuação da Tutoria EaD, o resultado foi muito satisfatório. Para "Sempre" e "Quase Sempre", o total foi de $89 \%$. Uma tutoria ativa, que acompanhou os alunos durante todo o curso, com feedbacks assertivos, que conduziram os alunos ao aprendizado e que incentivaram sua autonomia.

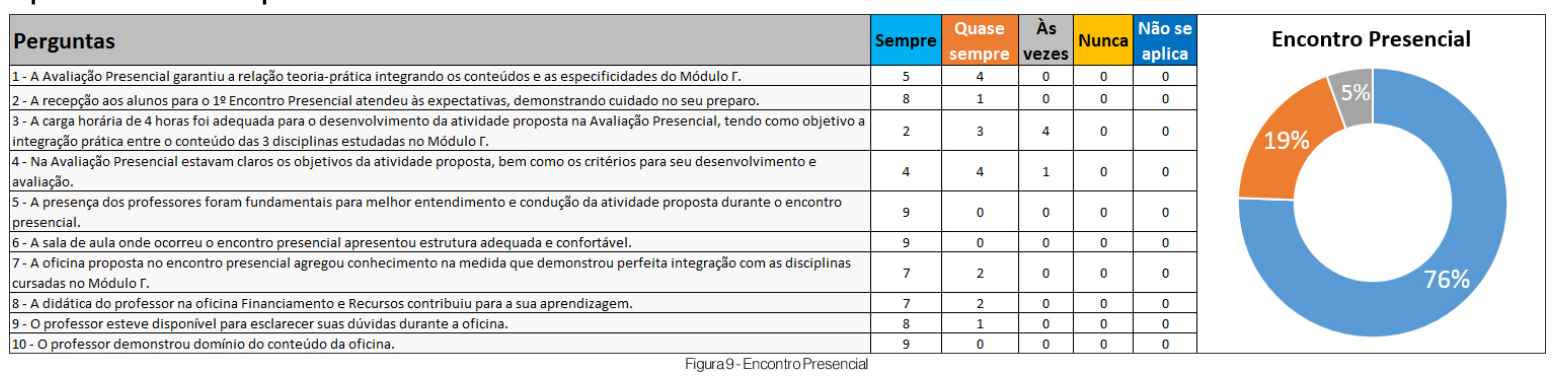

$\mathrm{Na}$ avaliação sobre o encontro presencial foram analisados itens como a avaliação presencial, recepção, carga horária e participação dos professores. Na soma "Sempre" e "Quase 
Sempre", o resultado foi de 95\%, um resultado altamente satisfatório para o fechamento do Módulo inicial. Foi o ponto alto do curso, com alunos totalmente motivados, satisfeitos com o curso. Um momento mágico, recompensando o trabalho de toda uma equipe. $\mathrm{O}$ item que teve a menor avaliação foi em relação à carga horária para a avaliação integrada, mas que interpretarmos estar mais ligada à vontade de nossos alunos em entregar uma produção audiovisual mais elaborada do que o tempo em si, mas mesmo assim repensamos para o Módulo seguinte. A notas auferidas, ainda que não constem desta pesquisa, foram todas satisfatórias, o que reforça nossa interpretação.

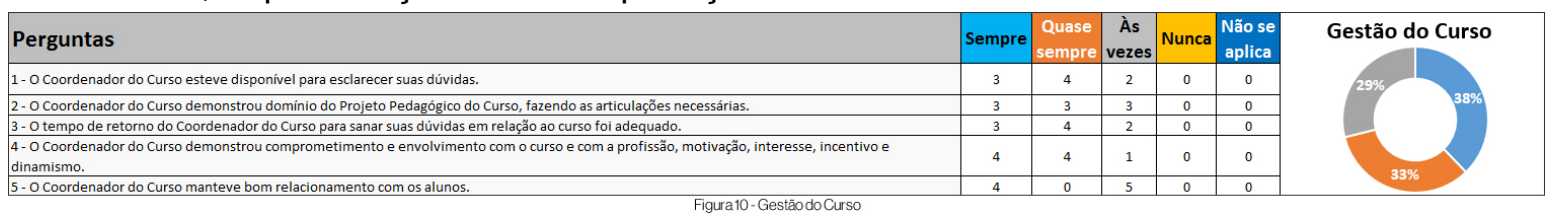

O Coordenador do Curso, profissional responsável pelo projeto pedagógico e gestão do curso, foi avaliado com $71 \%$ ao somarmos os itens "Sempre" e "Quase Sempre". O item com menor satisfação por parte dos alunos foi em relação ao bom relacionamento com os alunos. Ao avaliarmos sua atuação, não identificamos nenhuma falha de relacionamento. Identificamos, porém, o problema no pouco contato entre alunos e Coordenador do Curso. Este cenário já começa a mudar, com uma participação ativa, juntamente à gestão geral $\mathrm{EaD}$, do grupo Cine $\mathrm{BA}$, direcional à resolução de dúvidas em tempo real sobre o curso, desde questões técnicas até conceitos de sua proposta pedagógica. Certamente, para o próximo Módulo, a avaliação neste item será melhor.

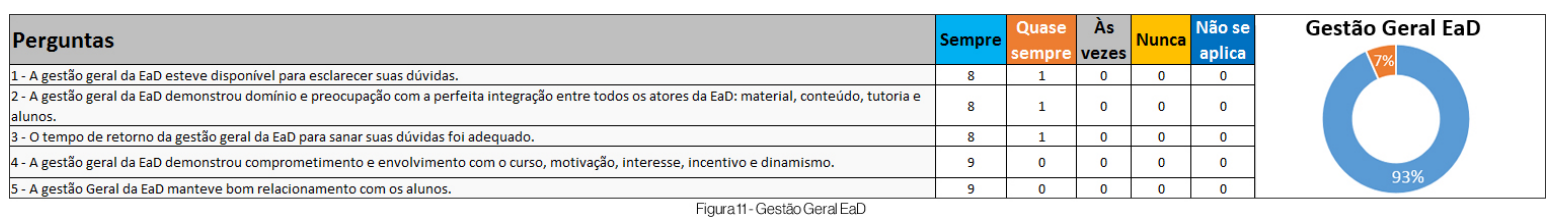

A gestão geral da $\mathrm{EaD}$ foi avaliada com $100 \%$ de satisfação dos alunos ao somarmos as opções "Sempre" e "Quase Sempre", resultado que compensa todo o tempo de dedicação desde o credenciamento da instituição para ofertar os cursos de pós-graduação na modalidade a distância, até este momento. Um projeto que levou cerca de 3 anos para se tornar realidade. A responsabilidade está em manter este \% ao longo do curso.

\section{CONSIDERAÇÕES FINAIS}

O que difere fazer um curso de pós-graduação EaD em Cinema na Universidade Belas Artes não é somente por ter mais de 90 anos de existência, mas pela experiência de cada profissional envolvido no projeto, desde aos professores tutores, suporte, designers e videoaula. Temos que levar em consideração a infraestrutura da universidade, os encontros presenciais, dinâmica, chats através do aplicativo WhatsApp e um material personalizado e criativo. Para o sucesso do curso é necessário olhar para o passado para prever o futuro, inovando na tecnologia, experiência com o usuário e promovendo uma imersão para a formação de um perito para área de Cinema.

\section{REFERÊNCIAS BIBLIOGRÁFICAS}

DALPIZZOLO, Daniel. A História do Cinema - O surgimento da Sétima Arte. Cineplayers, 2007. 
FILATRO, Andrea. Desing Instrucional contextualizado: educação e tecnologia. $2^{\underline{a}}$ Ed. São Paulo: SENAC, 2007.

Learning Design como fundamentação teórico-prática para o design instrucional contextualizado. Disponível em: . Acesso em: 18 mai. 2018.

HILLMAN, James. Psicologia arquetípica: um breve relato. São Paulo: Cultrix, 1995.

KENSKI, Vani M.; SCHULTZ, Janine. Teorias e abordagens pedagógicas.

LIMA, Jamila de M.; SILVA, Cláudia V. A. P. da; PAIVA, Clotilde M. de. Autonomia em Educação a Distância: Relatos a partir da prática de tutoria na disciplina Fundamentos Psicológicos da Educação em Dois Cursos de Licenciatura da UFPB Virtual. Disponível em:< http://www.abed.org.br/congresso2010/cd/352010000839.pdf>. Acesso em: 18 mai. 2018.

LIPOVETSKY, Giles; SERROY, Jean. Tela global - mídias culturais e cinema na era hipermoderna. Porto Alegre: Ed. Sulina, 2009.

MACHADO, Dinamara P.; MORAES, Marcio G. S. Educação a distância fundamentos, tecnologias, estrutura e processo de ensino e aprendizagem. São Paulo: Erica, 2015.

MORAN, Manuel José; Masetto, Marcos T; Behrens Marilda Aparecida. Novas tecnologias e mediação pedagógica. Campinas: Ed. Papirus, 2000. 